\title{
El humanismo simbólico en la escultura de Gustav Vigeland
}

\author{
Carlos d'Ors Führer
}

\section{ALGUNOS RASGOS BIOGRÁFICOS}

El 11 de abril de 1869 vió la luz cerca de Mandal, al sur de Noruega, el gran escultor Gustav Vigeland, hijo de un ebanista. Su padre era de carácter violento y desenfrenado, lúgubre ideología y religiosidad, y con un insaciable placer por el alcohol que imprimieron en el hogar una atmósfera opresiva. La gran mezcla de melancolia, pasión y frecuentemente también de fanatismo en el carácter de Vigeland fueron, con toda seguridad, herencia de la estirpe paterna. Por otro lado, sin embargo, delicadas cuerdas vibraron en su alma a lo largo de su vida heredadas, sin duda, del lado materno. Precisamente, estos grandes contrastes y enormes convulsiones fueron la fuerza motriz de su creación artística.

La talla en madera estaba, por entonces, muy extendida en el ambiente donde creció Vigeland. El abuelo materno era considerado un tallista muy trabajador y famoso por su precisión. Esta cualidad se puso pronto de manifiesto también en su nieto y conformó, en parte, su estilo creador. El pequeño aprovechó cada minuto libre para tallar y mostró precozmente gran talento y floreciente fantasía.

Nuestro escultor leyó mucho desde muy niño. Sus lecturas se centraron primordialmente en la Biblia y la Mitología, fuentes de su posterior creación.

Cuando tenía 17 años murió su padre. Dos años y medio después se puso en camino hacia Kristiania, donde habia ido anteriormente como 
aprendiz a un taller de talla en madera. Pero esta vez estaba firmemente resuelto a ser escultor y no se cuestionaba ningún otro trabajo.

El estremecedor libro de Knut Hamsun Hambre describe magistralmente las condiciones de vida en la capital noruega, azotada entonces de hambre, miseria, paro y depresión. Atónito vagaba Vigeland por sus calles, esperanzado y soñador. Pronto se le acabaron todos sus ahorros. Tenía que pasar las noches en escaleras de acceso, bodegas o tejados por no tener techo fijo. Sucedia frecuentemente que era descubierto y expulsado del lugar. El hambre y la necesidad roian sus entrañas. Un dia despertó - recién nevado- en las afueras de la ciudad medio congelado y extenuado, se sacudió y, rebelándose contra su propio destino, tomó una firme resolución. Con sus dibujos bajo el brazo se encaminó a la casa del escultor Brynjylt Bergslien para enseñárselos al viejo y experto artista. Pensó que tal vez encontrase oportunidad para calentar sus rígidas articulaciones, mientras Bergslien ojeaba sus dibujos. Esta vez la suerte, sin embargo, le fue favorable. El anciano escultor contempló asombrado los dibujos del joven visitante y exclamó: “iEs lo mejor que he visto en mi vida! ¿Quiere usted ser escultor?" La hora del destino de Vigeland había sonado. El anciano escultor le dejaba trabajar en su taller. Le proporciono 20 ciudadanos que le pagarían cinco coronas el primero de cada mes y un puesto en la Academia de Bellas Artes. Vigeland trabajó como poseído. Pobre, mal alimentado y nervioso vivía sólo para su arte.

Tras un año de estancia en Kristiania recibió becas para Copenhague, Londres, París, Roma, Florencia, Berlín. Incansable y ávido absorbía impresiones, se dejaba encantar pero también rechazaba influencias, manteniéndose siempre fiel a sí mismo, sincero y auténtico. Quería ser libre e independiente y que su arte fuera accesible a todos y no se ocultase únicamente en las casas de la gente rica. Prefería pasar hambre y necesidad que traicionar sus propósitos.

Su gran oportunidad le llegó con el cambio de siglo. Durante seis años tuvo ocasión de demostrar sus conocimientos con trabajos en la catedral de Nidaros de Trondheim. En esta época comenzaron sus primeras ideas sobre la "Sinfonía de la vida humana" a tomar forma: quería presentar la vida en todas sus fases a los ojos de la gente, desde el primer grito del recién nacido hasta el último suspiro del agonizante para transmitirlo a las generaciones actuales y venideras, y constituye lo que hoy es el magno conjunto de esculturas del «Froegner-park». Dejó voluntariamente este puesto de trabajo seguro y bien remunerado, volviendo al hambre y la inseguridad, para consagrarse a estas ideas. 
En 1943, tras ricos años de creación, murio Gustav Vigeland a los 74 años de edad. Fue una personalidad del contraste, en donde la fuerte luz choca con agudos contornos de sombra. Todo lo tenía que matizar el trabajo. Privadamente poseyó un humor muy considerable, era cariñoso con los niños y generoso con los que necesitaban ayuda. Su casa fue decorada por él mismo, dibujando todos los muebles. Manteles, almohadones, cortinas y tapices que salieron de las primorosas manos de su segunda esposa Ingerid Vilberg, fueron bocetos suyos. De este modo, su taller, que el municipio de Oslo subvencionó en el contrato de 1921 que hizo con el escultor para la realización del conjunto escultórico del Froegnerpark, no sólo es una enorme colección de sus esculturas, dibujos y bocetos, sino también su casa con su personal atmósfera. En ella permaneció muy frecuentemente Vigeland años enteros sin traspasar sus muros. Cuando el día 12 de marzo de 1943 el solitario artista dejó de existir era sólo una verdadera figura en el arte de los países nórdicos. Hoy, sin embargo, su gloria alcanza la historia del arte universal.

\section{SU GRAN OBRA: EL CONJUNTO DE ESCULTURAS DEL «FROEGNERPARK», UN CANTO A LAS DISTINTAS FASES DE LA VIDA}

\section{a) Proceso para la creación del magno conjunto}

El sueño de Gustav Vigeland era crear una obra que nunca antes se hubiera realizado por artista ninguno. Desde el cambio de siglo, el artista había soñado y trabajado en sus fuentes. En un principio, sin embargo, se tenía la certeza de que estas fuentes se levantarian en el centro de la ciudad.

En 1900 se habla sólo de un enorme cascarón con figuras. Los planes crecieron, sin embargo, y Vigeland añadió un nuevo modelo a sus fuentes con el mismo cascarón central, pero rodeado de 20 árboles de bronce. Entre sus ramas vivian seres humanos. Se trataba de una grandiosa epopeya de la vida desde la cuna a la tumba. En el borde de la base desarrolló el artista gran cantidad de relieves para expresar sus pensamientos sobre la vida de los hombres reiteradamente.

No había unanimidad acerca de dónde debían ser erigidas las fuentes, si delante del Parlamento del Storting o delante de la Universidad. 
Hubo gente, sin embargo, que se oponía a los planes del artista que entonces contaba 37 años. Eran de la opinión de que las fuentes fomentarían una "moral muy laxa». Una serie de los mejores autores noruegos se pusieron, no obstante, con entusiasmo al lado de nuestro artista. El dramaturgo Gustav Heiberg había expresado ya en 1901 que la capital de Noruega sería llamada un día "la ciudad de las fuentes". El historiador del arte, Jens Thiis, dió una serie de conferencias en las que alabó a Vigeland y sus fuentes. El poeta Björnson escribió entusiasmado sobre la obra de Vigeland. Influenciado por estos tres hombres, pero también con la oposición de muchos, un público numeroso acudió en romería para ver la maqueta en yeso de las fuentes al museo de arte industrial de Oslo. En un solo dia fueron 4.000 las personas que acudieron y dieron su donación para contribuir al levantamiento de las fuentes. Además, adinerados suecos del otro lado de la frontera regalaron grandes cantidades de dinero con la esperanza de que alguna vez puediera cumplirse el sueño dorado de Vigeland. En el curso de unos pocos meses se consiguió la suma necesaria.

Diez largos años pasaron en los que Vigeland trabajó denodadamente en la realización de su sueño, hasta que por fin vió terminada su obra. Habian puesto a disposición del artista el parque nacional "Frognerparken" (de origen agrícola) de 320.000 metros cuadrados de extensión. Esto suponía una gran oportunidad con la que muchos artistas hubieran soñado y un desafío fantástico para el ambicioso escultor. Cada metro cuadrado fue estudiado por el artista, cada árbol y cada planta está ahí donde quiso el maestro.

La obra creció, también los costos. Gran parte fue financiada con limosnas. Vigeland deseaba condiciones seguras de trabajo. Nada de sus planes debería quedar en el camino. Por eso en 1921 se firmó para el mundo un único contrato que permitia a Gustav Vigeland un trabajo continuado, sin interrupción. El artista se comprometió a ceder gratuitamente al municipio de la ciudad todos sus modelos originales. Se trataba no sólo de los ya realizados sino de cualquiera de los que realizase en el futuro. El municipio debería, sin embargo, por su parte construir un nuevo taller al artista. Ayudantes y material fueron subvencionados al principio con donativos privados, posteriormente el municipio se comprometió con estas obligaciones. El resultado fueron las 192 esculturas con 650 figuras que constituyen el Parque Vigeland de Oslo. Vigeland modeló personalmente todas las escultura en su tamaño normal. Las esculturas en piedra fueron esculpidas por escultores especialistas y los portones hechos por herreros, todo bajo la dirección del escultor. La obra está realizada en un lenguaje que pudiera entender cualquiera y su "Tema" era la "Vida de 
los hombres". Lo que le interesaba eran los seres humanos en las diferentes situaciones de la vida y las emociones comunes como lo son para cada uno de nosotros. Vigeland presenta al ser humano de todas las edades y en los grupos de árboles, los relieves en la fuente, en los grupos de granito y en las escaleras circulares siguen las estaciones de la vida de los seres humanos de manera que en conjunto refleja el ciclo de la vida desde el primer comienzo hasta la vejez y la muerte. Narra las penas y alegrías de cada persona, su lucha consigo mismo y los poderes, las relaciones humanas entre hombre y mujer, padres e hijos, jóvenes y viejos.

El conjunto to constituyen fundamentalmente cuatro partes: 1) EI puente; 2) La fuente con su cascarón sostenido por hombres y los árboles de la vida que la rodean; 3) El monolito o columna de figuras que se aprietan unas contra otras y sus 12 filas o rayos que irradian circularmente alrededor del monolito con sus 20 escalones y 36 grupos de granito, en la colina de Abel y, 4) La rueda de la vida, al final del parque. Todo ello se completaba con las puertas de acceso al parque y las ocho que rodean el "plateau» del monolito y sus 36 grupos escultóricos, en hierro forjado.

\section{b) El gran portal de entrada}

Al severo, colosal e imponente portal de entrada le confirió Vigeland misticismo y una fantasía plena de llamarada a través de sus simbólicas representaciones en formas circulares de sus partes centrales. En su canto a la vida recurre a la formación de lo animalesco, de lo que el hombre no puede desprenderse nunca del todo, porque está anclado en sí mismo. En los círculos de las puertas al lado del "Portal principal», vemos estilizadas lagartijas (fig. 1) que nos recuerdan, que desde hace millones de años, como lo han dicho bien alto sabios naturalistas, hemos evolucionado de las más primitivas formas de vida acuática a través de diferentes estadios a nuestro estado actual del ser, aunque lo animal sigue enraizado en nosotros. El gran portal central tiene presumiblemente, como toda la obra de Vigeland, un trasfondo simbólico. El camino de la vida es estrecho, angosto y difícil y su curso está predeterminado para nosotros. Tenemos que alcanzar todos el mismo fin y caminar a través de pequeñas y estrechas puertas en el himno de la vida. 


\section{c) El puente}

El puente, con sus 58 esculturas a ambos lados, fue el trabajo de sus últimos años de creación. Se han extinguido los fuertes y vehementes sentimientos y los afanes simbólicos de las figuras del monolito o de los árboles de la fuente. Es sobre todo el movimiento y la plasticidad de lo dinámico lo que fascina al artista, pero también la salud, la actividad, la energía y la vitalidad deslumbrante de estos infantiles y juveniles cuerpos. Emana de estas figuras la fuerza vital y primigenia. Los cuerpos rebosan solidez y son compactos y voluminosos. El propio Vigeland afirmaba que él buscó el tipo general del hombre y la mujer nórdicos; tipos puros, nítidos, casi radiantes.

A ambos lados del puente, al principio y al final del mismo, sobresalen dos columnas respectivamente, coronadas todas ellas con esculturas en las que la influencia del arte gótico (en cuyo estilo él había trabajado para la catedral de Nidaros) se revela muy patente. Ante todo, son dragones y seres humanos los alli representados. En tres de ellas lucha el hombre con el monstruo y se defiende. Se pueden interpretar estos dragones como símbolos de las oscuras fuerzas de la vida que deben ser combatidas. En este motivo el escultor ha representado sus propias vivencias: él que había conocido la lucha de la vida en toda su crudeza. La columna de la derecha del final del puente nos muestra un motivo muy diferente: una mujer se deja abrazar, casi voluptuosamente, por un animal monstruoso (fig. 2). Este motivo posee en su esencia un profundo sentido, que el espectador poco avisado no puede descifrar. Vigeland se relacionó, en la época de su estancia en Berlín, con un extraño y exaltado grupo de artistas. Todos ellos aborrecian a la mujer y veían en ella un ser perverso que como un vampiro succiona las fuerzas del hombre. Una opinión muy trágica, que tuvo su conmovedora expresión en literatura, pintura o escultura. A este círculo berlinés pertenecian el dramaturgo sueco Strindberg, el pintor noruego Munch y el filósofo alemán Nietzsche, entre otros. El lema de este último era el siguiente: "Si vas con una mujer, no olvides nunca el látigo". El grupo a la izquierda del comienzo del puente representa a un monje medieval luchando con el dragón-demonio (fig. 3). Los otros dos grupos del final del puente delatan la pesimista concepción de la vida de Vigeland. En uno, está todavía indecisa la lucha entre ser humano y demonio; en el otro, el monstruo derrota finalmente al ser humano.

El puente produce en sus múltiples y dinámicos motivos escultóricos un intenso sentimiento de danza de la vida. Ritmo, movimiento y animación traslucen y traducen estas compactas y sólidas representaciones. En 
su claridad y sinceridad, estas figuras de bronce son muy fáciles de comprender para el espectador. Vemos a niños que juegan con sus hermanos, a mujeres que acarician cariñosamente a sus hijos o que los levantan con alborazado rostro de maternal alegría hacia el cielo (fig. 4). Padres hacen gimnasia con sus hijos: se percibe formalmente su griterio alegre. Un padre sostiene inestablemente a sus hijos en cada uno de sus brazos y en uno de sus pies (fig. 5). Dos niños corren alborozados levantando llenos de entusiasmo sus brazos, manos abiertas y rostros hacia el cielo (fig. 6). Estos muchachos corren, ebrios de alegria, hacia la vida. Destacaremos también, por ejemplo, el niño enfadado y llorón que encanta a todos los visitantes y que es como un símbolo de Oslo y de este parque (fig. 7). Se le oye formalmente berrear y gritar y es el más querido de todos los turistas. O la joven muchacha que, levantando su doblada pierna izquierda, mira hacia atrás, estirando sus cabellos (fig. 8). ¿Personifica la alegría de vivir o se estira los cabellos de desesperación? Vigeland nos deja la decisión a nosotros mismos. El cariño y la veneración que el escultor siente hacia los ancianos podemos comprobarlo en la escultura en la que el abuelo lleva de la mano a su nieto y éste le mira lleno de devoción y admiración. Su fervoroso rostro es un estudio apreciable (fig. 9). La relación entre ancianos y niños está representada con indudable delicadeza y comprensión por el escultor a lo largo de toda su obra. Finalmente, las dos ruedas de seres humanos a ambos lados del puente y que son una anticipación a una de las últimas obras de Vigeland en el parque: "La rueda de la vida". En una de estas ruedas, un hombre lucha contra sus propios límites (fig. 10); en la otra, un hombre y una mujer son volteados inexorablemente por la rueda de la vida (fig. 11).

\section{d) Las fuentes}

Parece ser que la inspiración para su laberinto de fuentes la recibió Vigeland de una piedra de corales. Constan de un grupo central de un enorme cascarón, sostenido por seis gigantescos hombres y una serie de cuatro grupos de cinco árboles, cada uno en una esquina del rectángulo o pileta. Una base de grandioso mosaico negro y gris de 60 relieves rodea y cierra todo el rectángulo o pileta, que no sólo cumple una espléndida función decorativa. La fuente está constituida, repito, por seis gigantes que levantan esforzadamente un enorme cascarón (fig. 12). Esta fuente o cascarón es nuevamente otro símbolo de la vida. Significa las 
cargas que son necesarias sobrellevar cada uno en nuestra vida. Uno de los gigantes levanta su carga encima de su cabeza con juvenil e inquebrantable fuerza; otro, por el contrario, lleva el peso sobre sus anchas espaldas. Tal vez estos seis hombres llevando unidos la carga puedan darnos ejemplo de que cada carga es mucho más fácil de llevar, cuando todos sujetamos unidos. Vigeland expresó una vez que muchas de sus figuras "Soportan» todo cuánto él tuvo que soportar. Sea un ardiente cielo del atardecer, violentos nubarrones de amenazante tormenta, un invernal cielo gris plomizo, caiga la blanca nieve sobre el desolado parque o bien brille un resplandeciente sol de mediodia con su juego de luces y sombras, la contemplación de las seis gigantescas siluetas nos produce siempre el sentimiento de lo inmutable, nos acaricia el soplo de lo eterno. 27.000 litros de agua por minuto caen de la poderosa concha cuando las fuentes están en funcionamiento. Cae el agua con toda su fuerza primigenia como en las gigantescas cascadas de los fiordos nórdicos.

El motivo de los grupos de cinco árboles de la vida en cada esquina de la fuente es universal y posee creadora fantasía. Los cinco primeros grupos escultóricos arbóreos nos hablan de la infancia, los siguientes de la juventud, el tercer grupo del hombre adulto y el cuarto grupo de cinco árboles de la vejez.

En un árbol revolotean pequeños, todavía inconscientes niños alrededor, como si fueran abejas en un panal (fig. 13). Encantador es el del niño que, sentado en el árbol, lleno de curiosidad e interés dirige su indagadora carita infantil a la vida y al porvenir, mientras se chupa el pulgar (fig. 14). Sorprendentemente acechante medita sobre los misterios de la vida. Esta curiosidad, este anhelo de conocimientos, experiencia de aventuras nos atrapa en primer lugar, nos empuja continuamente en eternas búsquedas, indagaciones y en un permanente deseo de nuevas vivencias. Vigeland debió de representar a este muchacho como un autorretrato. Frecuentemente debió él de sentarse en los pinos que había detrás de la casa de sus padres y haber meditado, escuchando los rumores de la naturaleza. Vigeland cierra su muestra de la infancia con la forma femenina que ya no es una niña pero tampoco es todavía una mujer, que es arrojada sin aliento a la vida sin sospechar adonde es empujada. Llena de temor, salta por entre las ramas del árbol de la vida y oprime sus cerrados puños en su débil pecho. Vigeland la llamó «La golondrina» (fig. 15). Plena de dramatismo esta muchacha se arroja fuera del árbol. Este salto a la vida hemos de realizarlo todos alguna vez en la vida, tenemos que emanciparnos de la seguridad, de la protección y el calor de la casa paterna y arrojarnos a la aventura de la vida. El difícil momento de la emancipación, la pubertad comienza. Con profundo co- 
nocimiento de la psique humana y cálida comprensión Vigeland representa esta figura que presa de temor oprime sus cerrados puños sobre su pecho todavia infantil, mientras los ojos se abren bruscamente desorbitados y, de angustia, la boca se abre como en un grito. Esta "golondrina" apela de manera muy especial al contemplador. Nos reconocemos nosotros mismos en esta situación, en la que se mezcla el temor y la indefensión con la obstinación y la rebelión.

Años después nos encontramos de nuevo a la muchacha asomando por entre las protectoras ramas y esperando ver lo que la vida la depara (fig. 16). La acompañamos en su camino y somos testigos de su encuen. tro con el hombre. Vivimos su unión y su amor.

Para finalizar la cita de ejemplos de esta simbólica serie escultórica arbórea, señalaremos el de una mujer soñando sentada en un árbol, que muestra claramente la forma de un animal (fig. 17). Sus ojos están cerrados. ¿Escucha el latir de su pecho? ¿Sueña con el niño que está en e! arbol siquiente? El árbol sobre el que se sienta tiene cuatro patas y un rabo. La rama sobre la cual reposa familiarmente el brazo de ia mujer, se eleva en orgullosa curva hacia la copa en cuyo centro es visible una boca abierta. Las ramas se extiender como una cornamenta hacia los lados. Es una maravillosa composición, en donde se funden exuberante fantasia, simbolicismo sobre lo animalesco en el ser humano.

En los 60 relieves que decoran la superficie de la base o pileta entra lo venidero pronto en el corrompido pasado. El futuro está simbolizado a través de un niño que está en el cuerno de un monstruo prehistórico (fig. 18). La tierra tiene que estar dispuesta para la vida en germen; cráneos y huesos tienen que ser recogidos y quitados. Niños juegan intrépidamente con animales (fig. 19) y van creciendo. Un muchacho contempla. verdaderamente por primera vez a una muchacha y coloca timidamente su mano en su hombro (fig. 20). En otro relieve, una mujer acerca su pecho a un extraño animal, un unicornio (fig. 21). En otro, una mujer se sienta en los cuernos de un ciervo. Vemos agitarse a una pareja en la danza de la vida y después a un recién nacido. Un relieve nos muestra a una mujer que esta entre dos hombres (fig. 22). Dos seres humanos están suspendidos y el cabello de la mujer se ha enroscado en el cabello del hombre.

Finalmente llegamos a los relieves que describen a la vejez: un viejo hipócrita escucha con miedo "la voz de Dios". La muerte separa a dos amantes (fig. 23). Seres humanos tropiezan, caen en el abismo, se corrompen y se convierten en nada. Pero en la nada está el futuro y el 
círculo empieza de nuevo en el primer relieve y retorna el ciclo de la vida.

\section{e) El monolito y los 36 grupos de granito radiales}

El monolito es una idea en la que se había ocupado Vigeland desde su más temprana juventud. En germen se puede descubrir ésta en numerosos dibujos. A la pregunta de cómo se le ocurrió al escultor la idea del monolito el artista respondia que la idea le surgió de repente. Contaba que una vez llevaba él en su mano la fotografía de su gran relieve "La resurrección" enrollada con la representación hacia fuera, de tal forma que se le desplazó de la mano y se estrechó por arriba y de este modo tomó la forma de un cono. Este suceso parecer ser que le daría la inspiración para crear su célebre monolito, una composición de apretadas figuras humanas de bulto redondo en granito, para la cual hizo numerosos bocetos hasta alcanzar su resultado definitivo. Con ella creó una obra sin igual en el mundo del arte.

El resultado son 121 figuras humanas que se apelotonan; trepan unas hacia arriba, otras, son aplastadas. Unas ayudan, otras son auxiliadas. Unas han renunciado a la lucha, mientras que otras se encaminan jubilosamente hacia la luz. Cada uno puede darlas el significado que quiera.

Era una díficil empresa transportar el colosal bloque pétreo que pesaba 260 toneladas desde el fiordo Idde al puerto de Oslo y después a través de las calles de la ciudad. En 1928 se instaló en el lugar donde se encuentra, construyendose un andamiaje alrededor de la columna, colocándose los modelos de yeso al lado, junto al mismo bloque de granito. Tres canteros trabajaron durante 13 años hasta que el monolito estuvo terminado. El 20 de agosto de 1943 pudo contemplar el público alli presente los pormenores de esta impresionante columna de 17 metros de altura.

Cuando nos ponemos delante de esta obra de Vigeland, nos sentimos pequeños e indefensos. Las palabras no nos sirven para describir lo que subyuga a la vista. El monolito es, posiblemente, el punto más alto en la creación de este genial artista, la cima de su vida artística, la coronación de su parque, el "crescendo" de su sinfonía sobre la vida. Hans P. Lodrup escribe conmovedoras líneas sobre esta obra: «El monolito es una apoteosis de la humanidad toda que lucha y sufre, una simbólica representación de la vida en la tierra en su más profundo y 
múltiple significado. Da lugar a muchas interpretaciones y significados: la lucha de la vida; la lucha por nuestra existencia; el anhelo hacia las estrellas; la búsqueda de los hombres por elevados conocimientos del cielo y de Dios; la transición de la vida en la tierra a una más elevada existencia. Todo esto vive en esta maravillosa obra artística. El joven y el anciano, el niño y el adulto están representados en continuo movimiento hacia arriba y riacia lo alto. Uno ayuda, el otro es ayudado; unos se apretan desconsideradamente sobre otros; otros se retuercen en penas; otros flotan en su espiritual estado de felicidad; nuevamente otros caen; otros trepan a la punta. Algo de la omnipotencia de la Naturaleza nos atrapa al contemplar esta columna de piedra en la que la inconcebible múltiple creatividad del artista alcanza su punto culminante".

El propio Vigeland decía de su obra: «Esto es divino. Es un regalo. No es uno dueño de ello. No está uno subordinado a su voluntad. La creación artística no es ningún juego, es un sufrimiento. Cada uno puede interpretar este monolito como quiera. Esta es mi religión».

Se nos aparece esta columna de cuerpos humanos como la resurección. Por debajo de todo, los seres humanos yacen pasivamente (fig. 24), pero después se elevan, se aprietan y se agolpan conjuntamente hacia lo alto, hacia el cielo, hacia la liberación (fig. 25). Escuchamos la música de Beethoven, cuando nos dejamos subyugar por el virtuosismo escultórico de Vigeland, su soberano dominio de la forma y del movimiento, el ritmo y la rotunda limpieza de su juego de lineas.

Conmovedora es la punta o vértice del monolito, en donde Vigeland ha esculpido a mujeres y niños que se extienden hacia el cielo, el sol y hacia la luz. Vigeland queria ante todo que hubiera niños en la cúspide, porque el niño está en la cima entre los mortales, va más lejos, está más cerca de Dios. A pesar de que ningún visitante puede alcanzar a ver las figuras más elevadas del monolito, el escultor las ha modelado con infinita y al modo de un artista medieval, al preguntársele que porqué se daba tanto afán en ello, contestó: “iDios lo ve!". En este sentido trabajaba Vigeland. $Y$ no aceptaba ninguna falta.

El monolito se alza como un símbolo del consuelo y de la esperanza. Nos revela la esperanza en una vida en el más allá, la aspiración a la liberación de lo terrenal y al triunfo de lo espiritual. Nuestro espíritu pervive en las generaciones venideras y se alza de nuevo hacia lo alto en la larga cadena que conduce a la eternidad.

Se ha especulado sobre si los 36 grupos de figuras de granito que en forma de rayos solares se agrupan en 12 radios de tres grupos alrededor del monolito no estuvieran pensados como reloj solar que con sus 
sombras marcase las horas del día y señalase las épocas de la vida humana (fig. 26). Lo cierto es que estos grupos escultóricos de granito se nos aparecen radiantes de majestuosidad, originalidad, plenos de concentrada fuerza expresiva y, al mismo tiempo, intemporales. Nos evocan al arte antiguo egipcio, griego y romano en su imperturbabilidad. Estas figuras actúan como mensajeras del pasado y también como testigos de! futuro, al mismo tiempo. Se han reunido en su fuerza expresiva y riqueza. plástica. Su gran tamaño fue muy discutido porque rompia totaimente con el tipo dinámico y grácil de sus figuras de bronce. Pero hemos de pensar que es un material totalmente distinto de modelar, el granito, una piedra rocosa muy sometida a la corrosión y que es necesario lavaria y limpiarla. regularmente. Cada uno de estos grupos pétreos se tardó año y medio en realizar.

Siguiendo la disposición de las manecillas del reloj, se nos muestra el comienzo de la vida en un ovillo de pequeños cuerpos de niño, el simbolo de la familia, donde padre y madre forman casi un pequeño nido. para ampararios y protegerlos, todo brilla de intimidad y amor. La Madre Tierra reúne inclinándose a los pequeños en su regazo. Nuevamente nos encontramos al abuelo con sus nietos (fig. 27), y la madre tiene suficiente fantasía para jugar con sus niños, sin necesidad de juguetes. Se coloca como caballo y sus coletas sirven como riendas (fig. 28). Encantador es el grupo de las dos muchachas que cuchichean, juntando celosamente sus cabecitas, olvidándose de prestar atención a su hermanito que juega con una serpiente. O también el de dos muchachos que miran atentamente a un punto del cielo (fig. 29). ¿Miran un avión o un pájarc? ¿O más bien contemplan su futuro con un punto de mira elevado hacia ic alto? Dramáticos son finalmente algunos grupos de ancianos, como el de las dos ancianas que miran angustiadas su futuro, presagiando su muerte próxima. La situada más próxima al espectador hace el expresivo gesto de temor de taparse la boca con su mano, mientras que el otro brazo protege a su anciana compañera resignada (fig. 30).

Cuando se le preguntó a Vigeland lo que significaban los grupos de granito y el monolito se cuidó de contestar: "Los grupos de granito son fáciles de comprender; ellos son la realidad. Lo que encierra la columna pertenece ai mundo de la fantasia".

Todo este conjunto del monolito y los 36 grupos de granito está cercado por ocho puertas en hierro forjado. Después de que Vigeland había concebido el portal principal, del que ya nos hemos ocupado, diseño estas ocho puertas que cierran el "plateau» del monolito. Cada puerta tiene dos alas con figuras en el campo. Hay muchachas cazando mariposas, mientras muchachos cortan ramas; tres muchachas caminan 
del brazo entre flores y conversan alegramente (fig. 31). En otras hay hombres oue conversan o rien.

\section{1) La rueoa de la vida}

De $\$ 933-1934$ creo el artista esta grandiosa rueda, que está constiuida oor siete seres humanos que están unidos indisolublemente. una corona de cuerpos humanos de tres generaciones, que no tiene principio ni fin (fig. 32). Tiene un diámeiro de ires metros.

Esta escultura expresa magistraimente el mensaje ciei eterno caminar por la vica del ser humano. Siete años tras la muerte de Vigeland Le colocada como ultima escultura al final de parque en una eievacion que perminía divisarla desde iejos. Con profundo conocimiento en los misterios de la vida el artista ha entrelazado siete figuras humanas de tres generaciones como una corona o rueda aándonos con ello un claro eiemplo de una de las regias esenciales de la vida: las generaciones se engranan, se completan, se necesitan y se buscari entre si.

For ultimo diremos que enrre la oase o plataforma dei monoito y "La rueda ce la vida" hay un reioj de sol en cuyo zccalo vigeland ha esculfido relieves que representan los 12 signos del zociaco (fic 33).

\section{in. CONCLUSIÓN}

El parque de escuituras de Froegner es la obra principal de vigeiand Se ha discutido y hablado inucho de esta obra desde su finalizacion. ralabras de censura y alabanza, rechazo y ciega acmiracion se nan mezclado y slicedido. Fero la obra de un gran artista tiene que provocar aisputa por fuerza.

No obstante, si queremos tener una visićn lo mas compieta posibie de la grandiosa obra de Vigeland ienemos que visitar también su tailer, aue desde 1947 es asimismo su museo. Aqui encontramos la explicación je su fantástico contrato con la ciudad de Osic. Fodemos contempiar iodos sus estudios para sus sensibles composiciones. 
Encontramos aquí sus monumentos plenos de fantasia sobre Abel, Wergeland y Camilla Collet. También podemos ver una serie de bustos de retrato, como el de lbsen (fig. 34), que son tan intensamente característicos que dejan tras de sí una impresión imborrable. El museo contiene además innumerables bocetos, grabados y dibujos que enriquecen y profundizan el entendimiento del más grande escultor de Noruega.

El arte de Vigeland expresa como no podia siquiera sospecharse un altísimo grado de ternura, sensibilidad, profundidad, belleza y pureza a un tiempo. Es la más completa y rica expresión de la creatividad noruega que ha existido nunca. En la fuerza de su universalidad y la riqueza de su producción, su arte se sitúa en un lugar privilegiado no sólo del arte noruego, sino de todo el arte mundial. 
El humanismo simbólico en la escultura de Gustav Vigeland

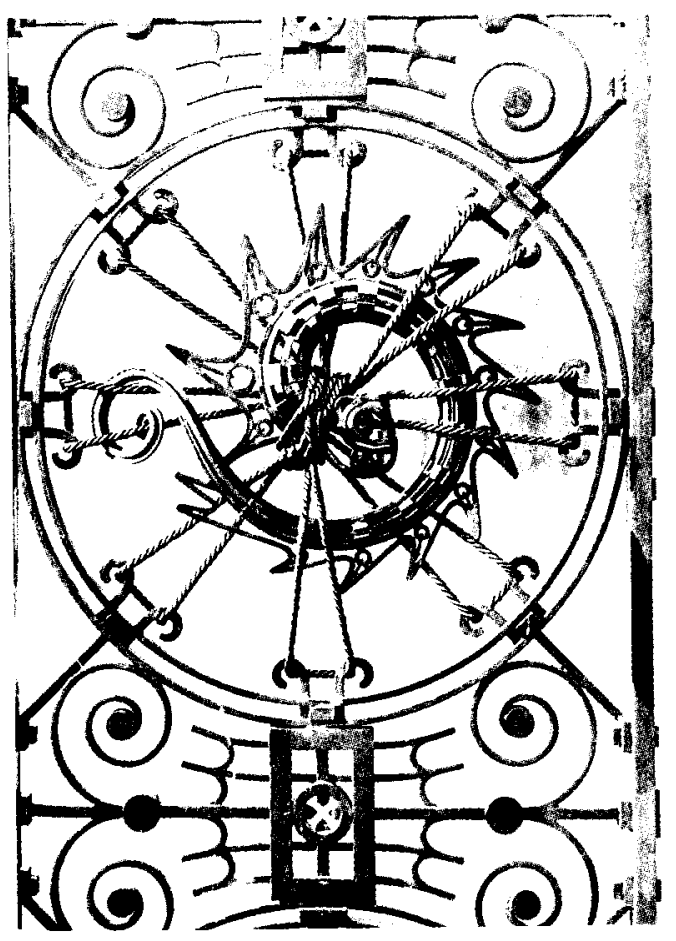

Fig. 1

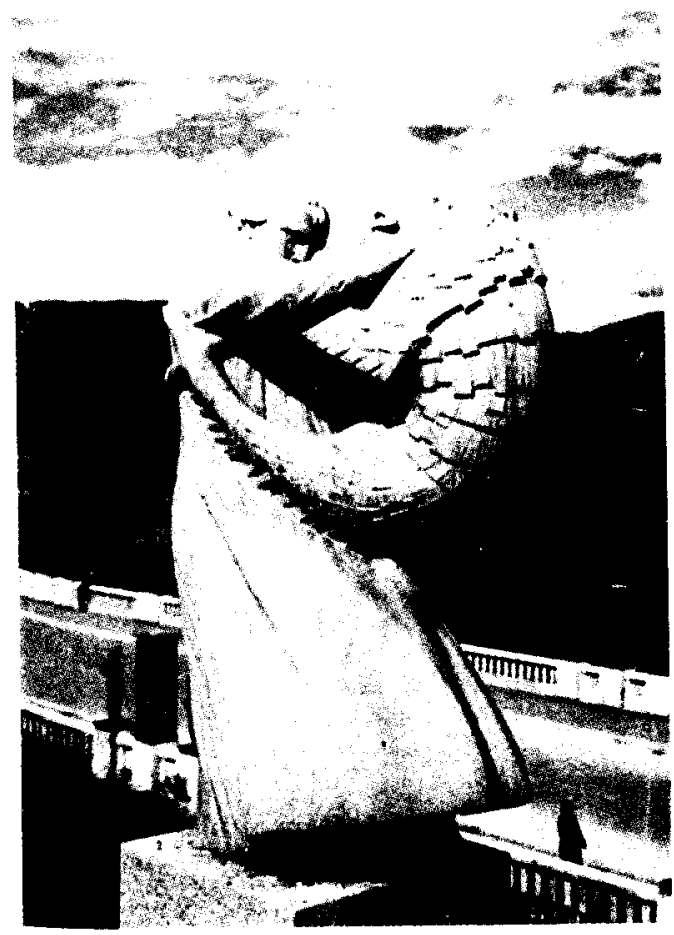

Fig. 3

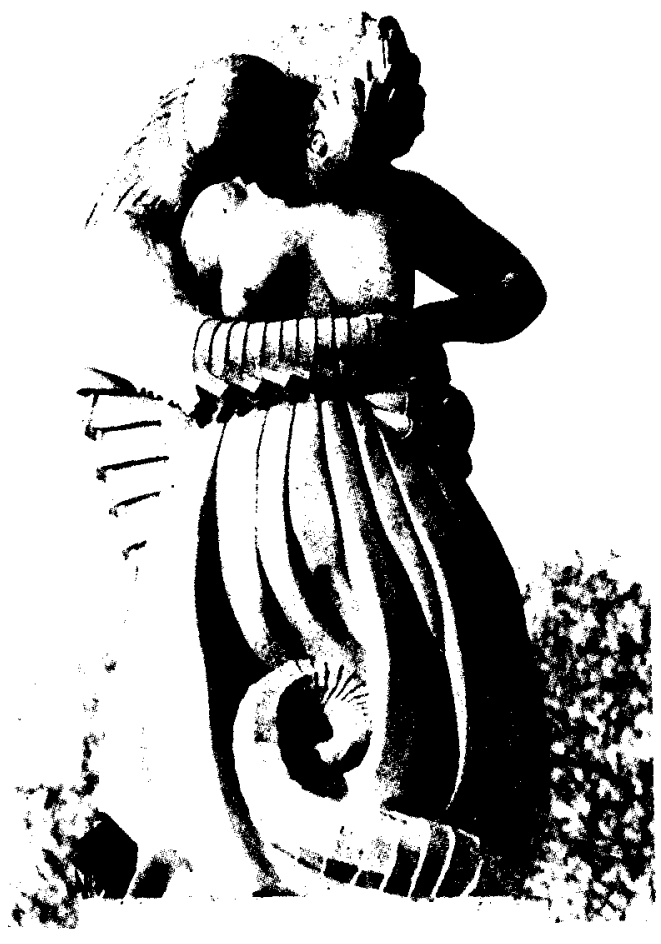

Fig. 2

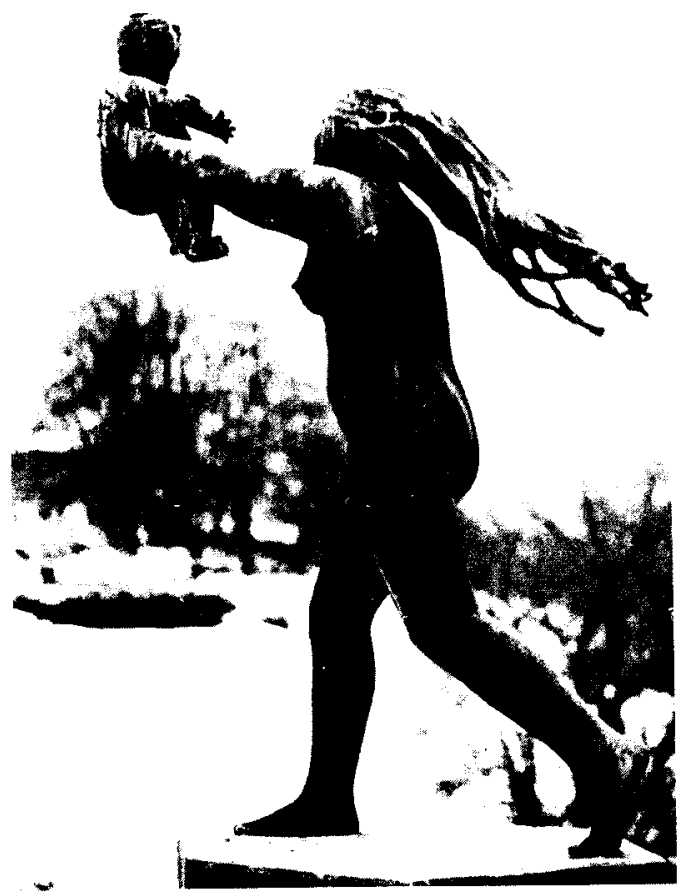

Fig. 4 

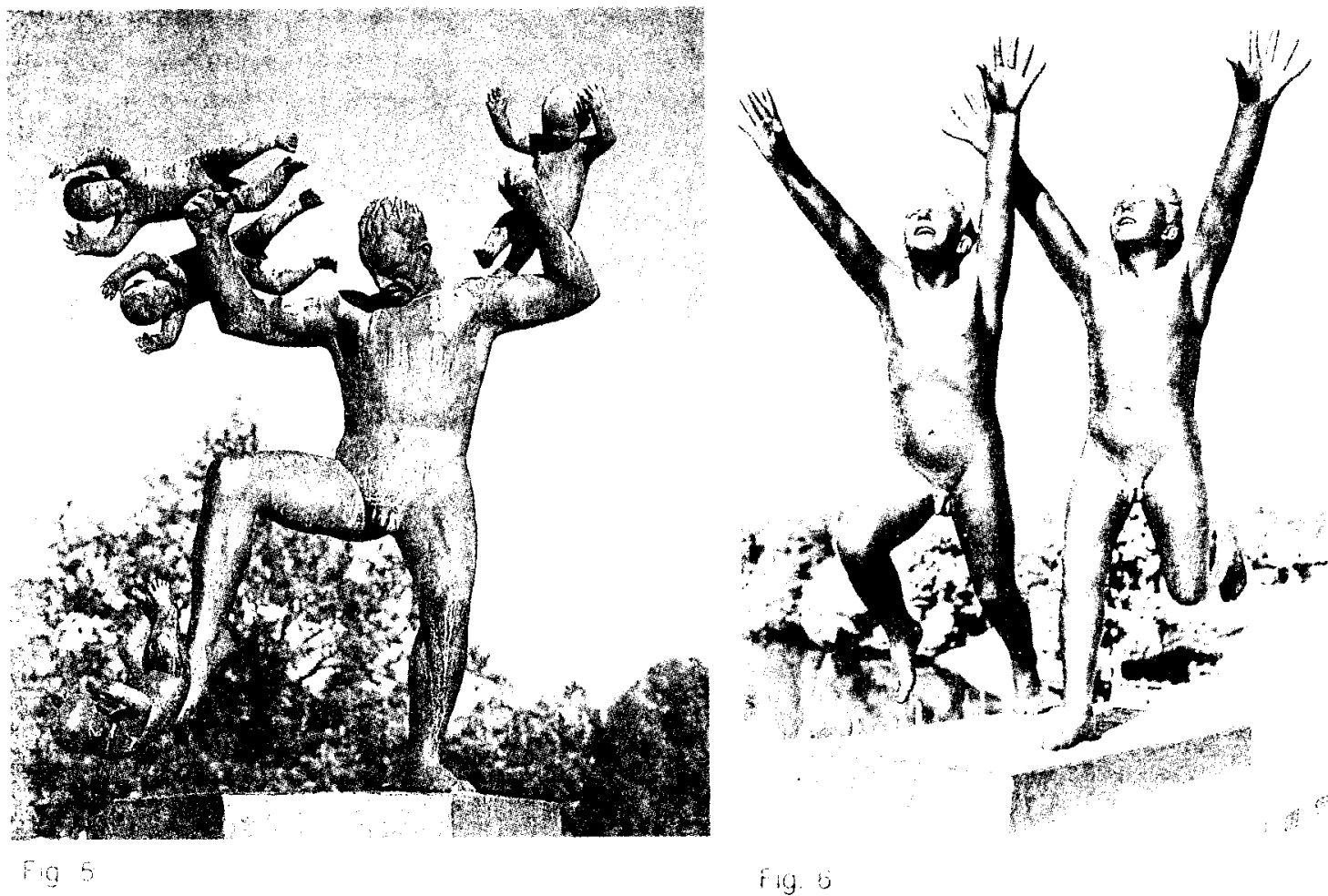

itg. is
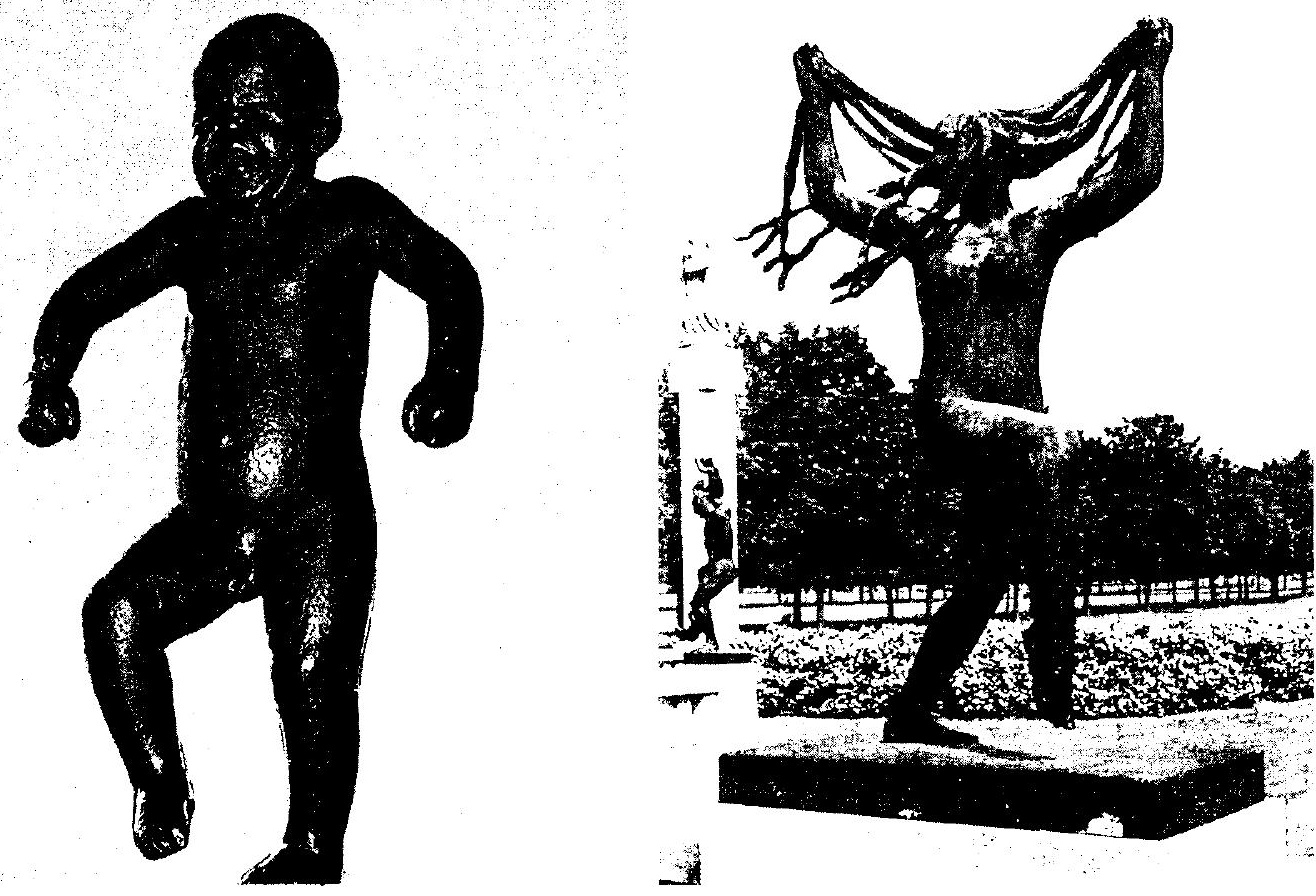

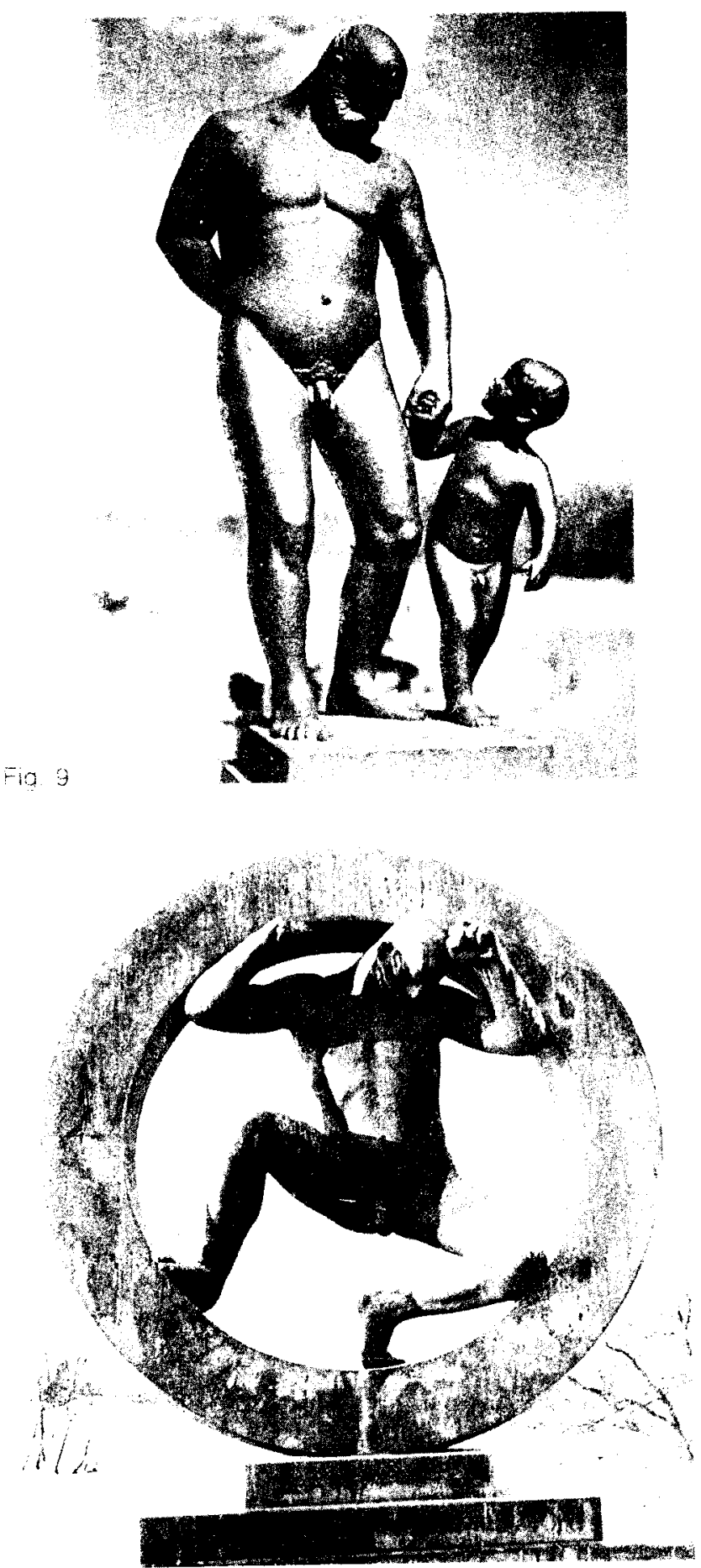

Fig. 10 

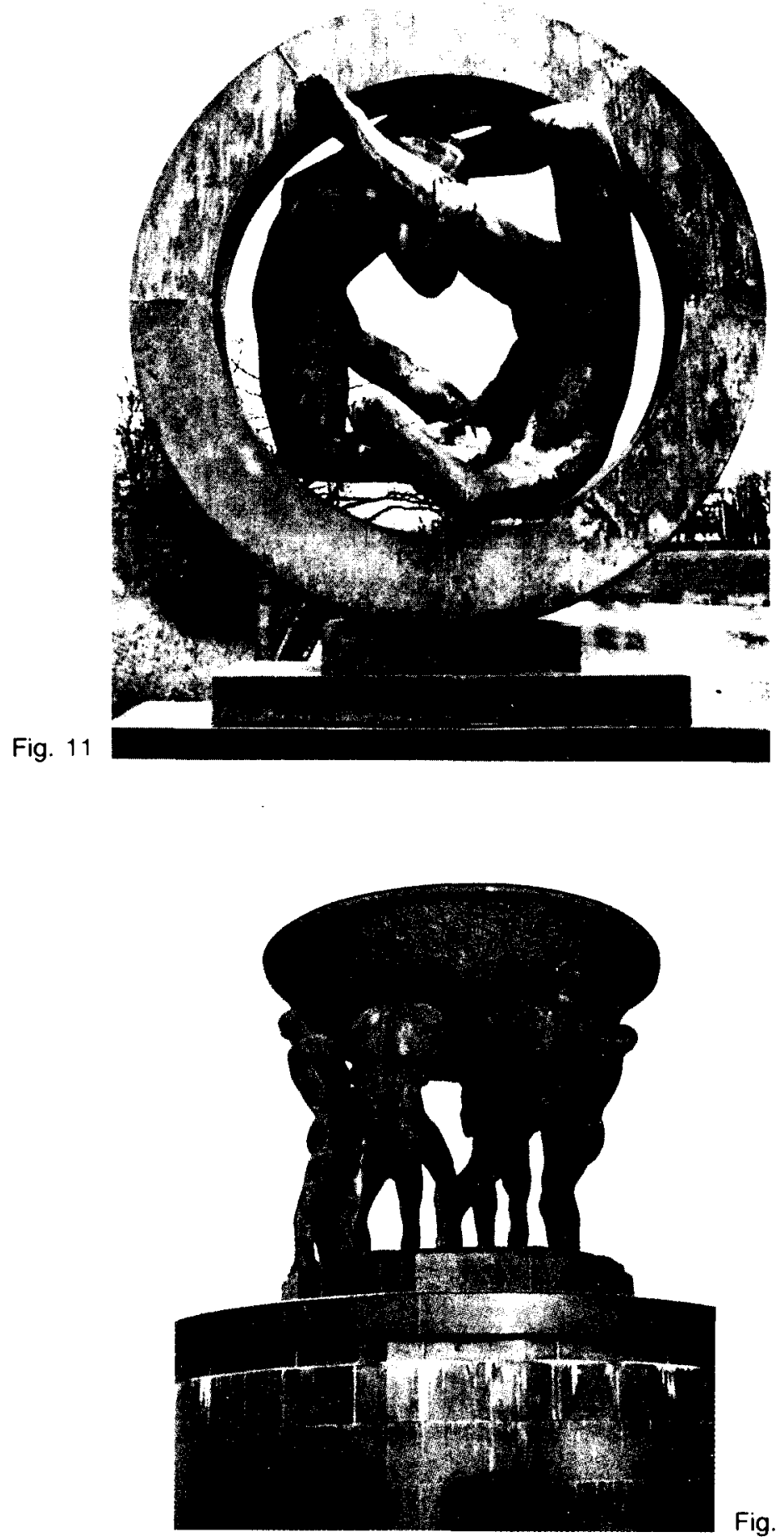

Fig. 12 

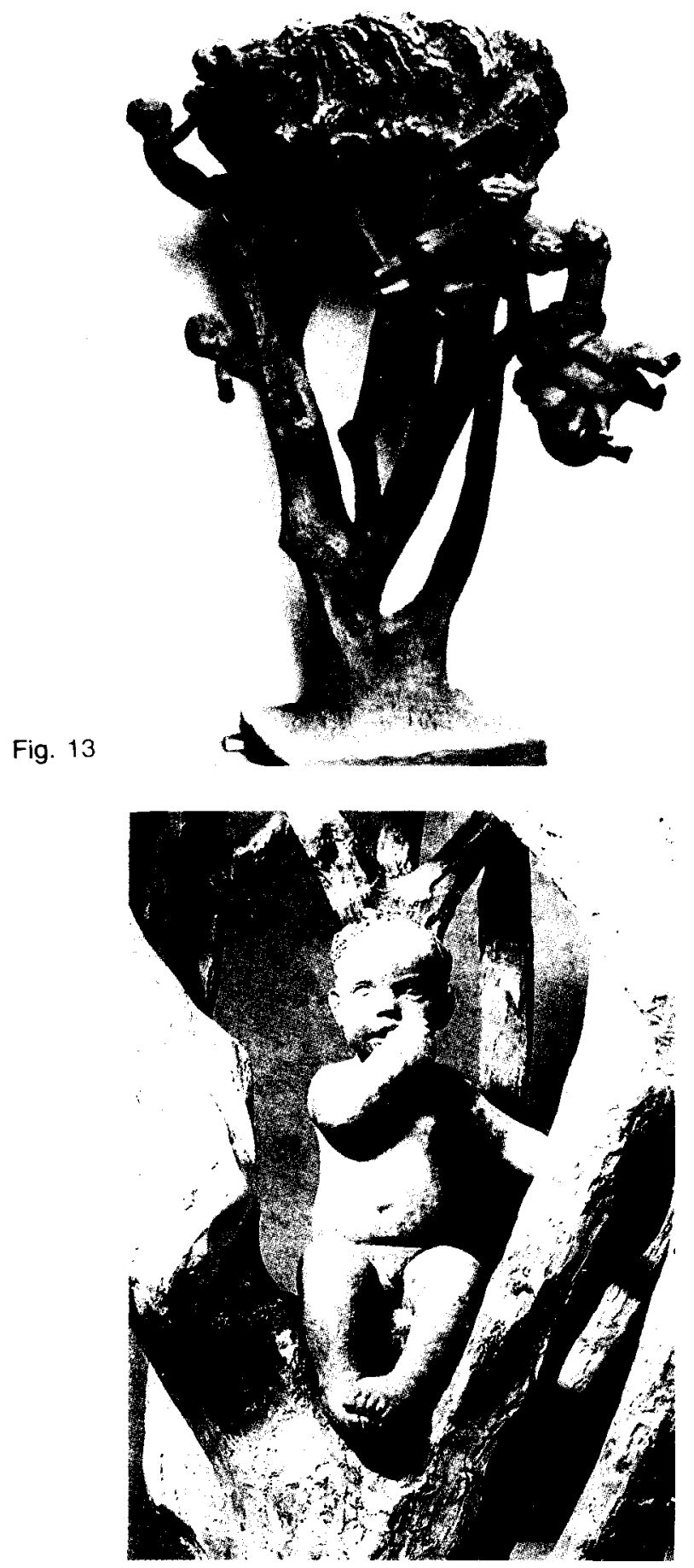

Fig. 14 

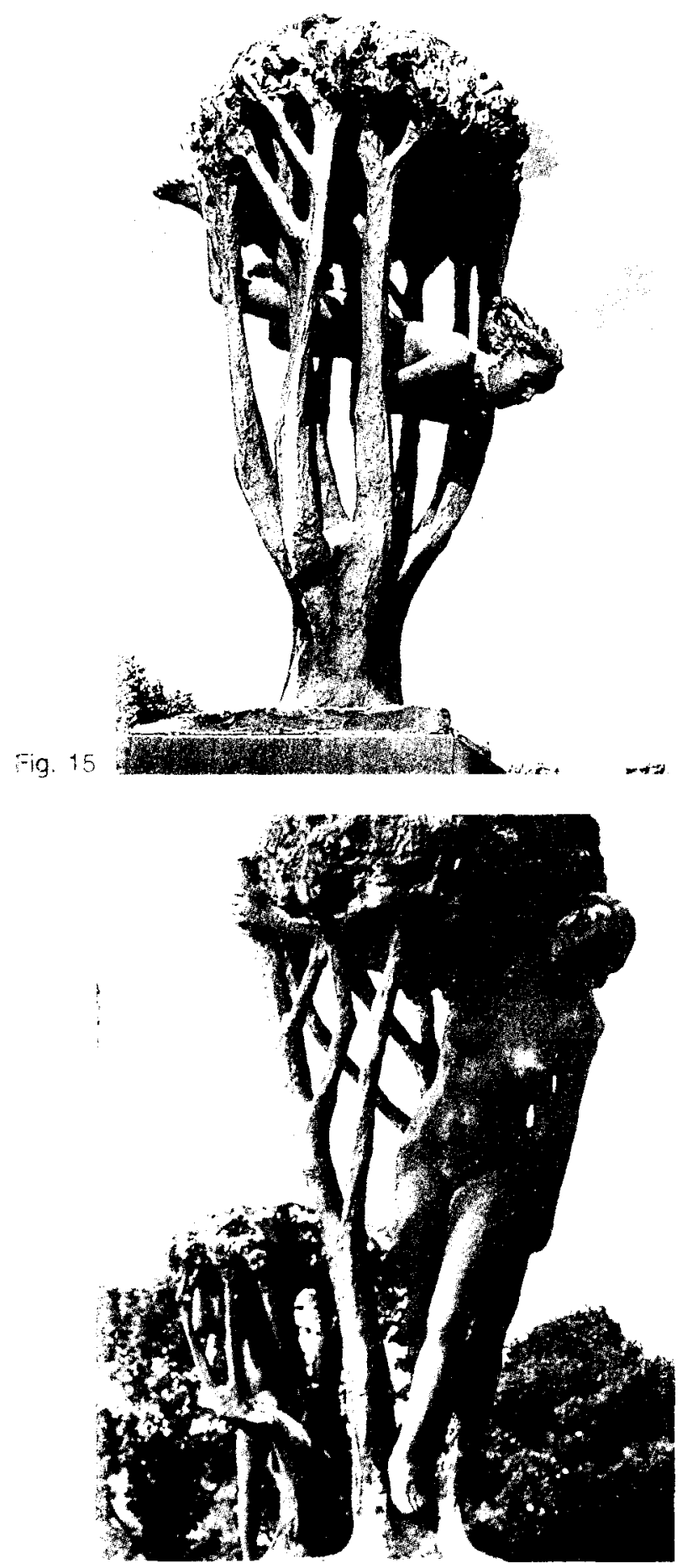

Fig. 16 


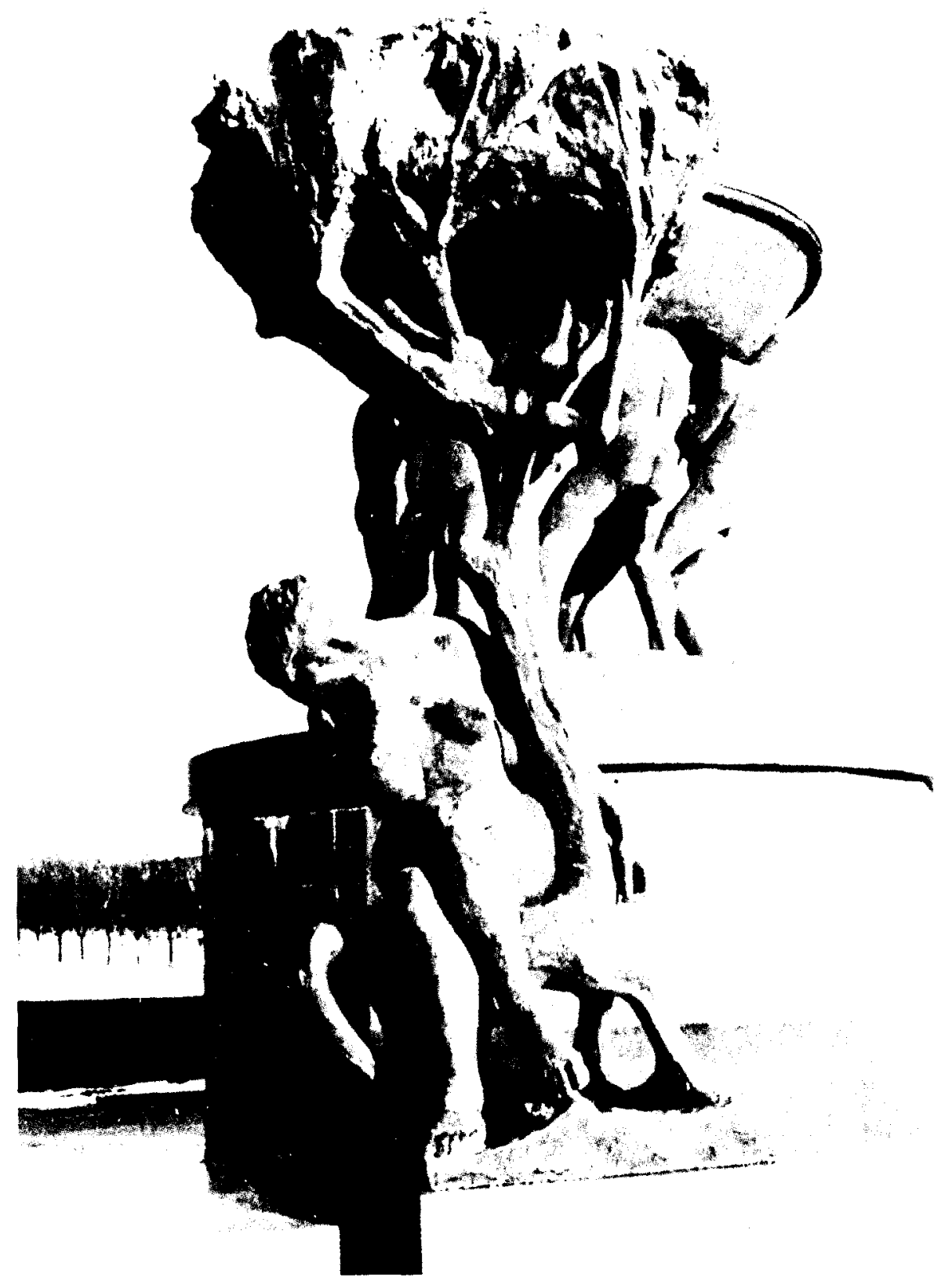

Fig. 17 


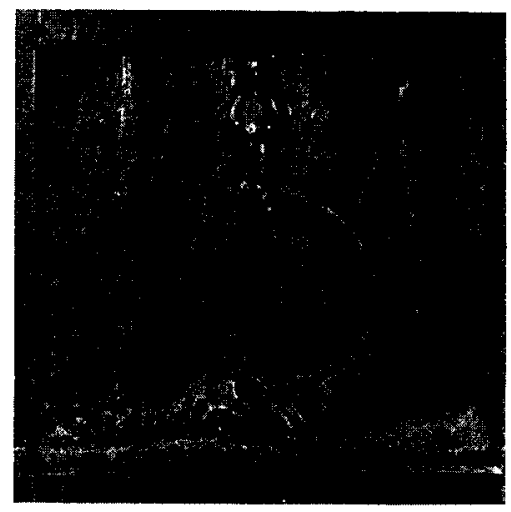

Fig. 18

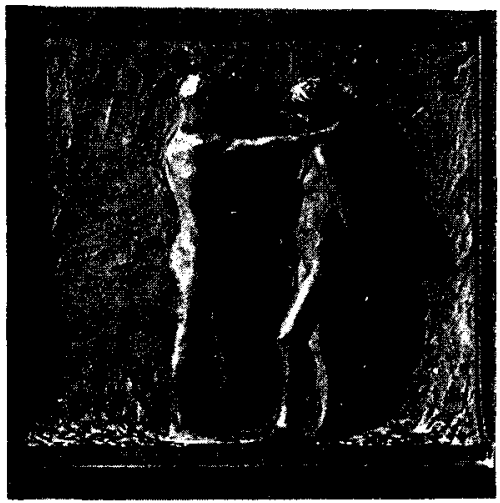

Fig. 20

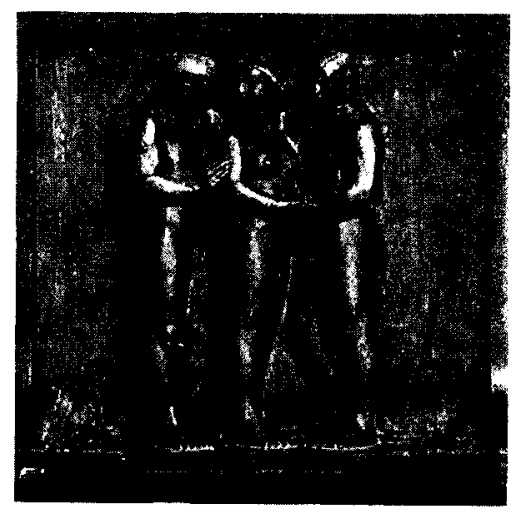

Fig. 22

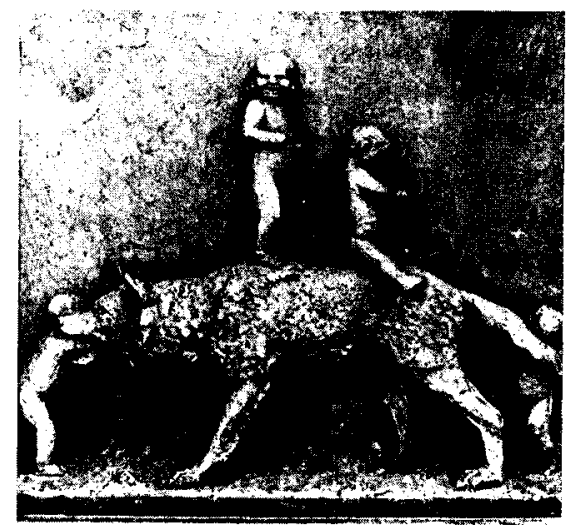

Fig. 19

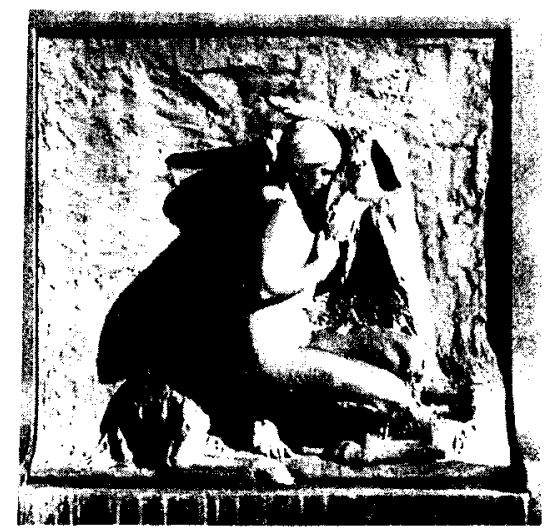

Fig. 21

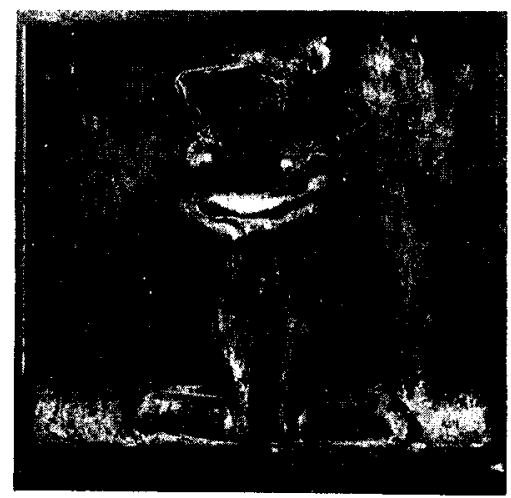

Fig. 23 


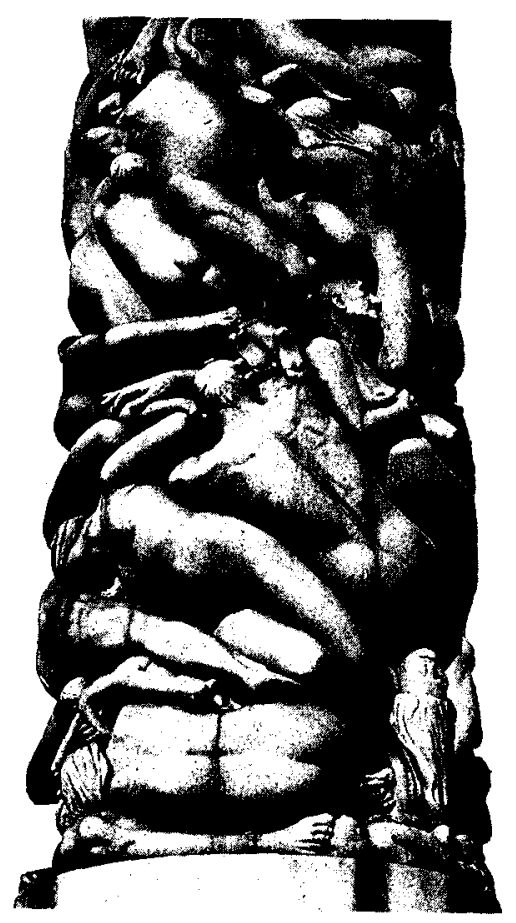

Fig. 24

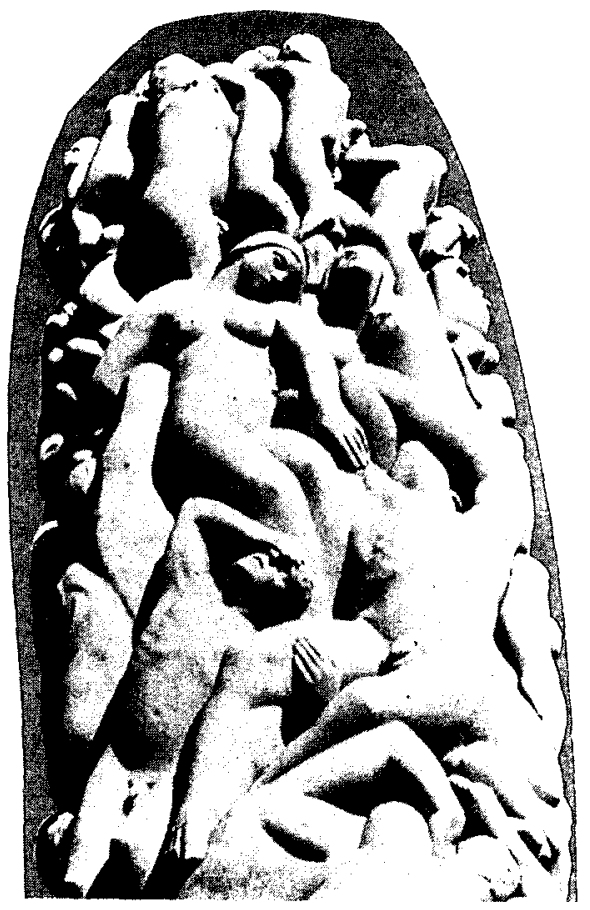

Fig. 25

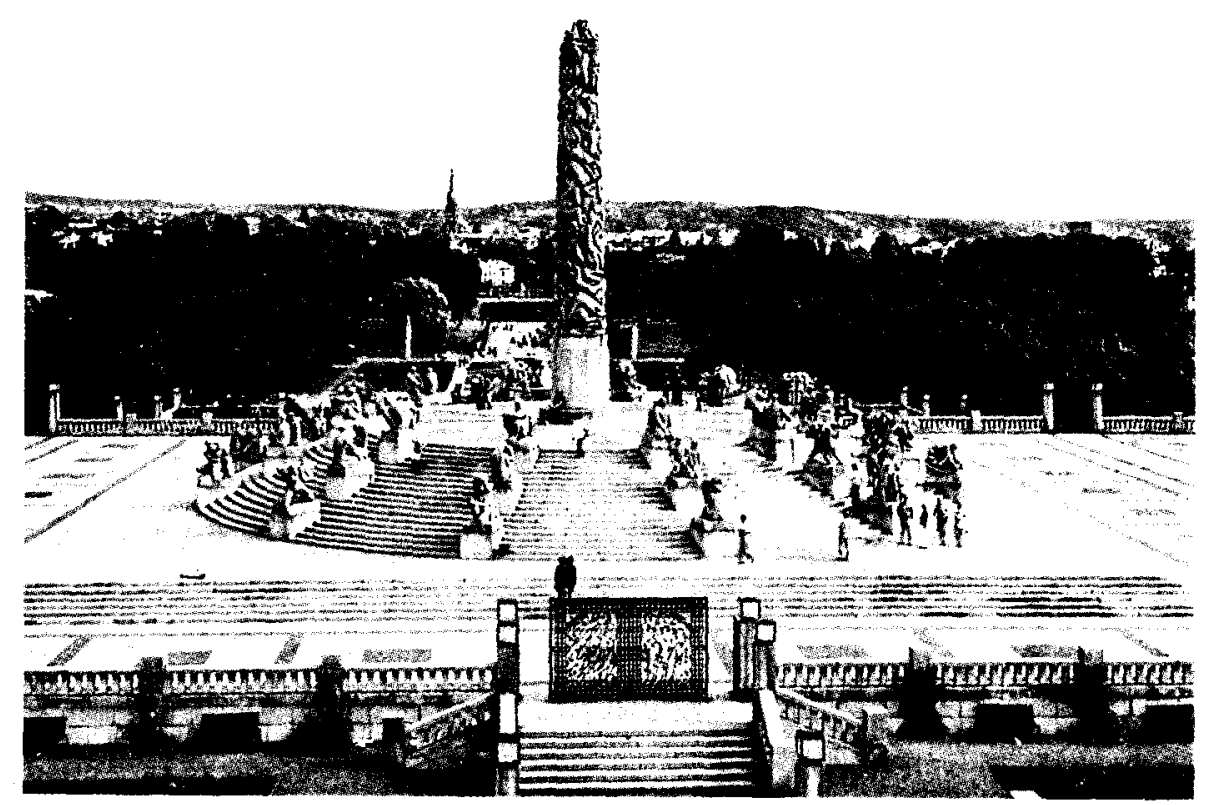

Fig. 26 

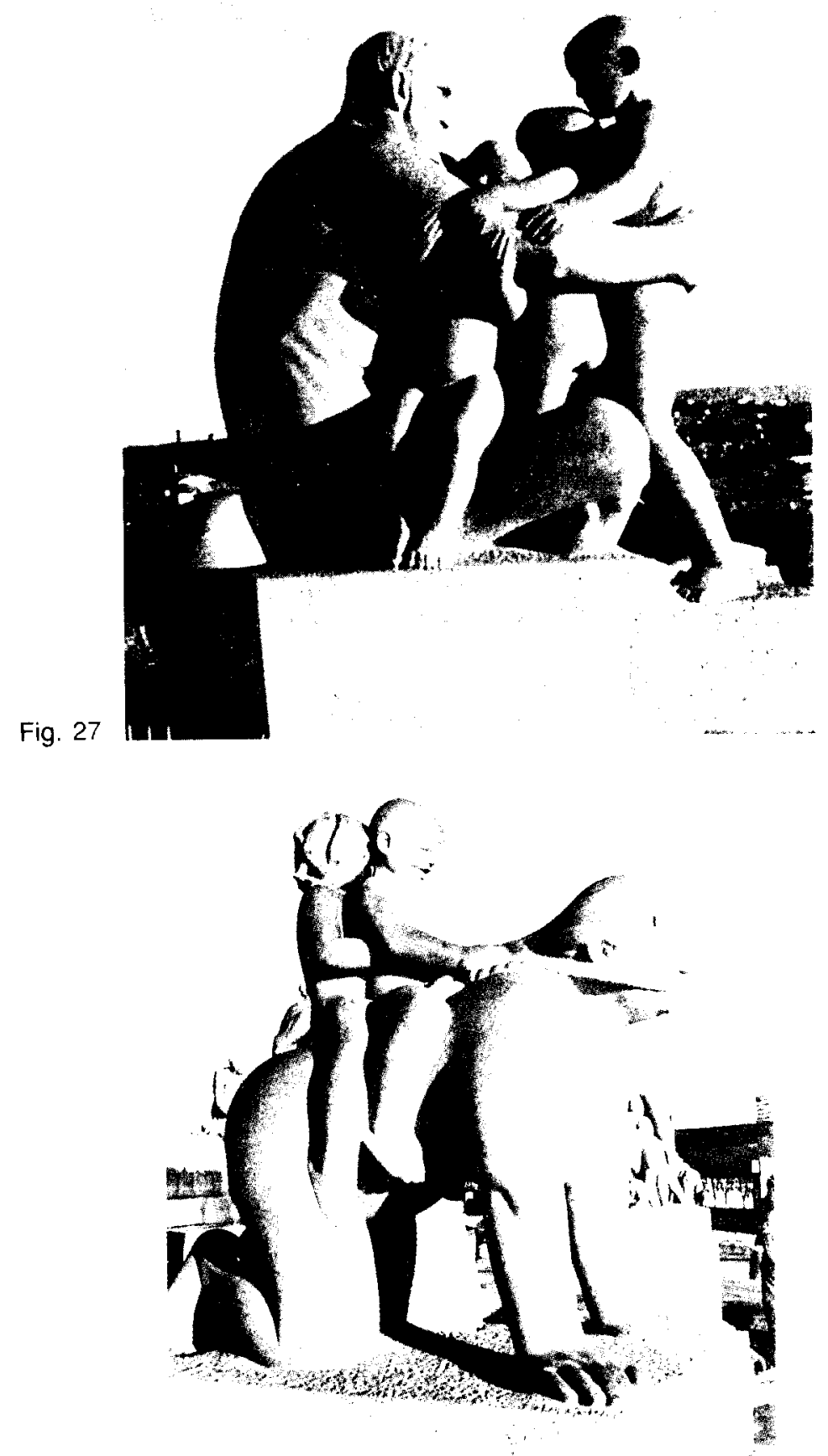

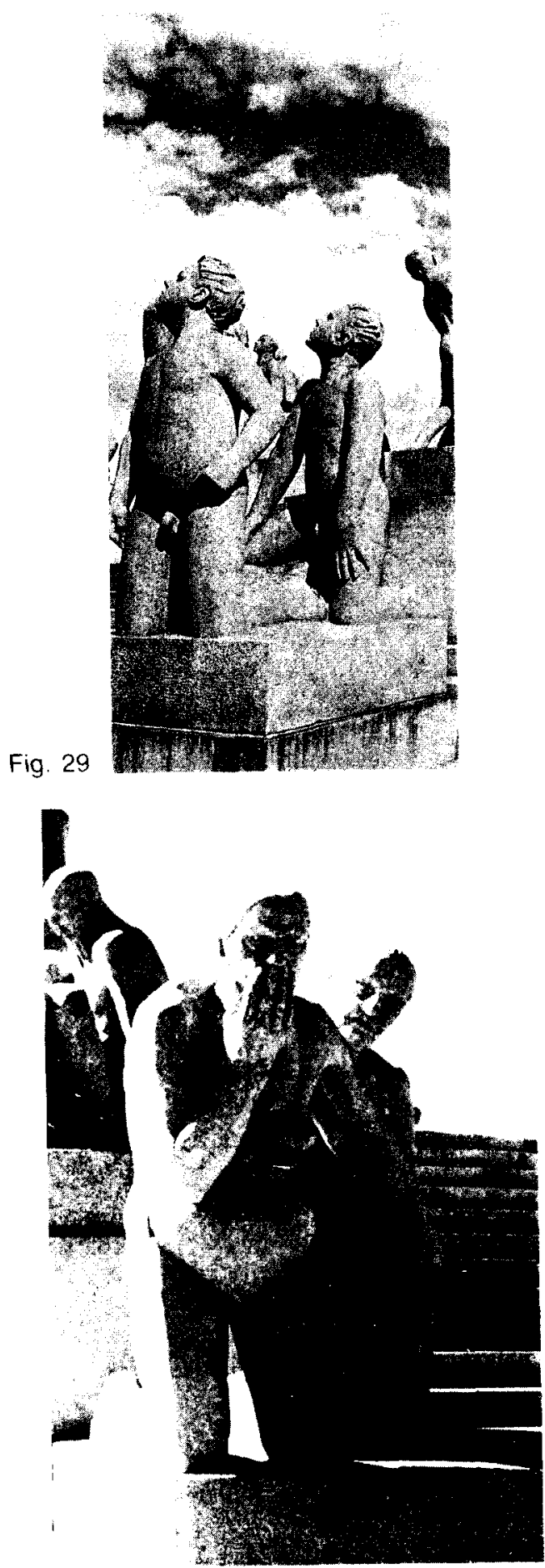

Fig. 30 


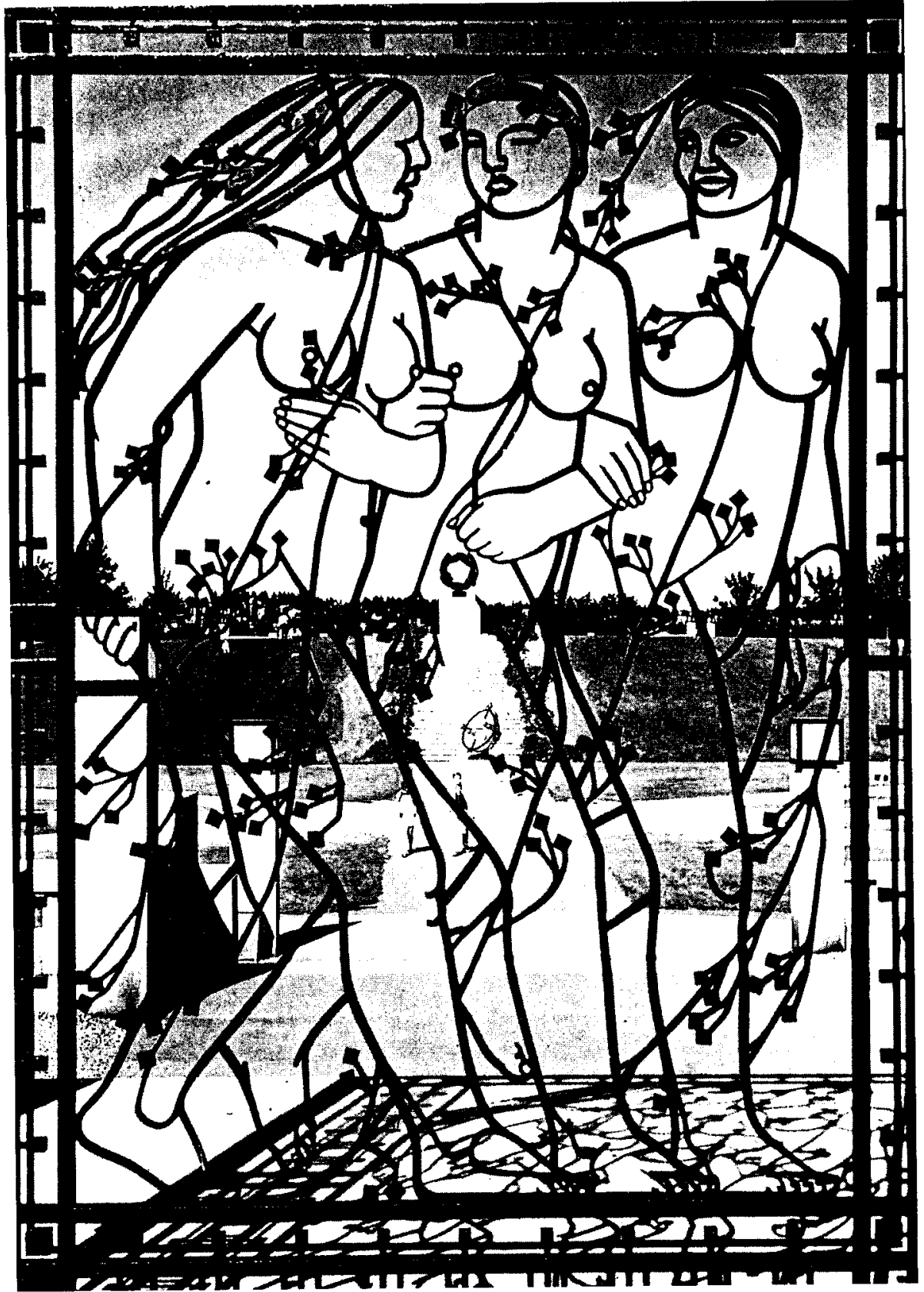

Fig. 31 


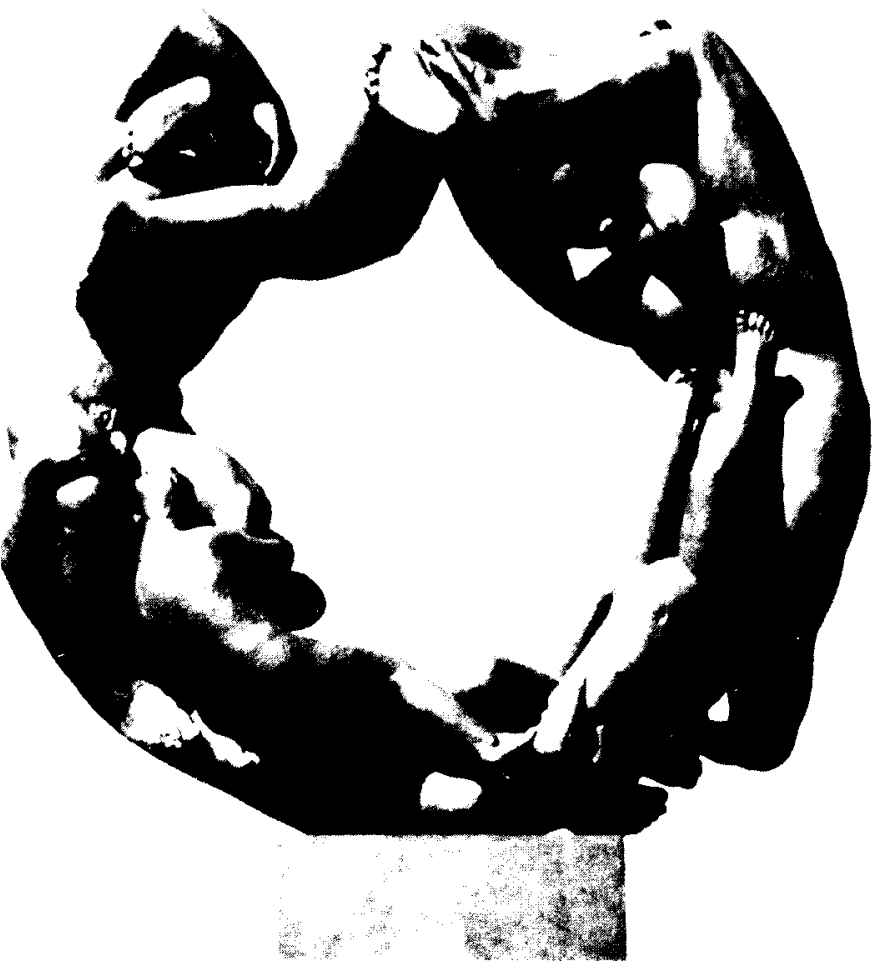

Fig. 32

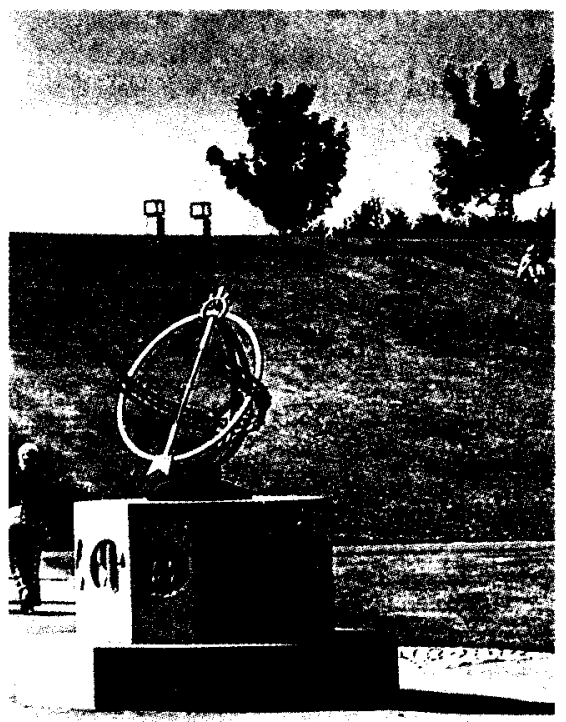

Fig. 33

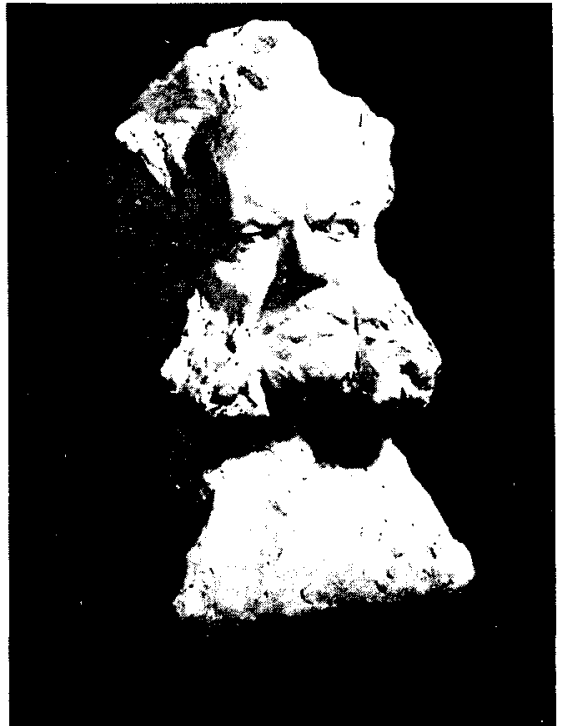

Fig. 34 